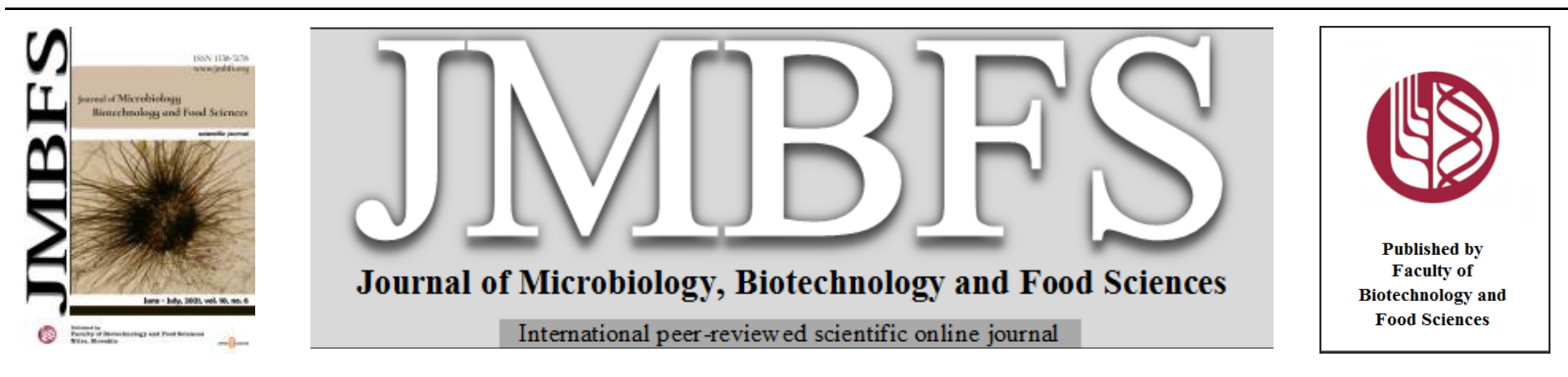

\title{
AMEDMENT STABLE KOJIC ACID PRODUCED BY NON-TOXINOGENIC ASPERGILLUS ORYZAE USING FIVE LEVELS CENTRAL COMPOSITE DESIGN OF RESPONSE SURFACE METHODOLOGY
}

\author{
Ghada Abd-Elmonsef Mahmoud*, Abdel-Naser A. Zohri \\ Address(es): \\ Botany and Microbiology Department, Faculty of Science, Assiut University, Assiut 71516, Egypt.
}

*Corresponding author: ghadamoukabel@aun.edu.eg

https://doi.org/10.15414/jmbfs.2683

\section{ARTICLE INFO}

Received 24. 2. 2020

Revised 23. 1. 2021

Accepted 1.2. 2021

Published 1. 6. 2021

Regular article

OPEN $\partial_{\text {Access }}$

\begin{abstract}
Kojic acid is a remarkable secondary metabolite of Aspergillus with various hot spot applications in the field of medicine, cosmetics, food, agriculture, and chemistry field. However the needs of stable large production with safe cultures still need continuous searching. Microbial kojic acid concentrated highly on Aspergillus species especially Aspergillus flavus group. Ten isolates of A. flavus and A. oryzae isolated from various Egyptian sources were producible of KA in range $0.091 \pm 0.01$ to $66.81 \pm 0.95 \mathrm{~g} / 1$. Aspergillus oryzae (no. 4) that give maximum production was selected as non-toxinogenic safe isolate for optimizing the production by five levels CCD design of RSM. Maximum value of kojic acid with $108.4 \%$ increasing was $139.24 \mathrm{~g} / \mathrm{L}$ (predicted $135.8 \mathrm{~g} / \mathrm{L})$ using glucose $(+1 ; 200 \mathrm{~g} / \mathrm{l})$, yeast extract $(+1 ; 6 \mathrm{~g} / \mathrm{l}), \mathrm{KH}_{2} \mathrm{PO}_{4},(+1 ; 1.5 \mathrm{~g} / \mathrm{l})$ and $\mathrm{MgSO}_{4} .7 \mathrm{H}_{2} \mathrm{O}(+1 ; 1 \mathrm{~g} / \mathrm{l})$ through run (24). Model significance and validity tested by $R^{2}$ values of KA was 0.987 , DM 0.989 and CS 0.9831 and calculated with Derringer's desirability function as 0.937 . Optimized kojic acid showed stability against different range of heat stress from $40^{\circ} \mathrm{C}$ to $100^{\circ} \mathrm{C}$ during five continuous hours which may attribute that microbial product usually more stable than synthetic ones by attaching it with other active groups that guaranty more stability under stress conditions. Aspergillus oryzae (Ao-4) represents promising safe isolate for industrial kojic acid production with highly product stability using this significant valid experimental design.
\end{abstract}

Keywords: Kojic acid, Kojii, Fungi, Derringer's desirability function, industrial, stability

\section{INTRODUCTION}

Kojic acid is a major heterocyclic natural secondary metabolite related to weekly organic acid with molecular formula $\left(\mathrm{C}_{6} \mathrm{H}_{6} \mathrm{O}_{4}\right)$ with chemical structure 5Hydroxy-2-(hydroxymethyl)-4H-pyran-4-one (Brtko et al., 2004). It has been used highly in cosmetics products like skin-lightning products for its high inhibitory effect against tyrosinase (alternative of hydroquinone) (Wang $\boldsymbol{e t}$ al. 2014), is an iron and copper chelator prevent oxidation, hyperpigmentation, photodamage, and skin wrinkling (Briganti et al., 2003). It's used as skin lotions, soaps, creams, and other products (Faig et al., 2017). Also, it has large pharmaceutical applications such as antibacterial (Gram-negative), antiviral, antiinflammatory properties, pain relief, anti-aging, antidermatophytic, radical scavenging agent, biocompatibility medical and antiprotozoans (Prignano et al., 2007; Gonçalez et al., 2015; Syamsul et al., 2017). In agriculture it's used as antimicrobial, pesticides and insecticidal agent (Burnett et al., 2010). In Japanese foods (soybean paste, sake, soy sauce, and mirin) include as a preservative food antioxidant agent (Sheikhshoaie et al., 2017).

Kojic acid was produced originally from Aspergillus oryzae (Machida et al., 2005) in high quantities, however it also produced by Aspergillus sp., Penicillium sp., Acetobacter sp., and Bacillus sp. (Masse et al., 2001; Machida et al., 2005; Pildain et al., 2008; Vasntha et al., 2014). Aspergillus spp. were known to produce large amounts of kojic acid like A clavatus, A awamorii, A fumigatus, $A$ candidus, A. flavus, A. parasiticus, A. oryzae, and A. tamarii (Kwak and Rhee, 1992; Lee et al., 2006; Terabayashi et al., 2010; Chang et al., 2011; Prabu et al., 2011; Mahmoud et al., 2020a). Researcher's didn't ignore the risk of aflatoxin produced by Aspergillus strains, Madihah et al. (1996) showed that aflatoxin synthesis by kojic acid producing isolates like $A$. flavus could inhibited using suitable medium and culture conditions, also both kojic acid and aflatoxin follows different synthesis pathways in Aspergillus sp. (Basappa et al., 1970). Several methods were used for KA analysis including column chromatography, voltammetry, mass spectrometry, thin-layer chromatography, high-performance liquid chromatography but the easiest way was spectrophotometry detection as its generate brown reddish color when react with ferric chloride (Tanigaki et al., 1980; Dobias and Brtko, 1985; Frisvad, 1987; GoTo et al., 1990; Pildain et al., 2008).
Medium constituents especially the carbon and nitrogen sources are the highest parameters that effects on kojic acid production. Glucose considered the best carbon source used highly for kojic acid production as to the structure similarity with kojic acid. Scientist suggested that, kojic acid formed directly from glucose during the fermentation without any carbon chain cleavage into smaller fragments (Kitada et al., 1967; Basappa et al., 1970; Chang et al., 2011).

A classical optimizing method depends on studying one factor each time neglecting the interaction between factors that could increase the production by $100 \%$ or more, while statistically optimization used the parameter interactions in convenient runs number saving time and reduce the error possibility by introducing the predicted values (Xu et al., 2003; Chen et al., 2009). Experimental designs represent a new way for production optimization which could easily save the experiment time and introduce possible parameter combinations with various KA quantities. Response Surface Methodology is one of the effective experimental designs that explain the quantitative experimental data by simultaneously multivariate equations (Vohra and Satyanarayana, 2002; Desai, 2008). It is widely utilize in the bioprocess technology and optimization of numerous types of growth parameters giving the best combination of the parameters with responses prediction (Grahovac et al., 2014; Kong et al., 2014).

Aspergillus flavus group, especially A. flavus and A. oryzae, represents the most significant producing fungal group of kojic acid (Machida et al., 2005). However most of studies discussed the effect of fermentation parameters on kojic acid production using one- factor only method and neglect the interaction between these parameters and its effects in increasing the production process especially by using statistical tool like response surface methodology. So, the aim of this study was design to examine the ability of some A. flavus and A. oryzae isolates to produce KA. Also, studying the interaction process between different medium constituents on the KA production and evaluate the stability properties of the microbial kojic acid from non-toxicogenic A. oryzae were aimed. 


\section{MATERIAL AND METHODS}

\section{Fungal isolation}

Ten isolates of Aspergillus flavus group (A. flavus and A. oryzae), were isolated from soil, milk, and spoiled nuts samples using direct and dilution plate methods and incubated at $28 \pm 1^{\circ} \mathrm{C}$ on potato dextrose (PDA) medium containing (g/l): 200 , scrubbed and diced potato; 15, dextrose; 20, agar; 1000 distilled water. Medium initial was justified to $\mathrm{pH} 5.6$ with $1 \mathrm{~N} \mathrm{HCl}$ and autoclaved for $20 \mathrm{~min}$. at $121^{\circ} \mathrm{C}$. Sterilized medium supplemented with bactericidal agents (chloramphenicol) (Booth, 1971; Mohamed and Mahmoud, 2018). Generated fungal isolates were identified according to its growth, macroscopic and microscopic features described by Raper and Fennell (1965), Domsch et al. (1980) and Bennett (2010). Cultures examined using Olympus CX41, Japan microscope for microscopic properties after staining by lactophenol cotton blue for clear image analysis (Ibrahim et al., 2020). Purified isolated maintained on PDA slants, preserved at $4 \pm 1{ }^{\circ} \mathrm{C}$ and sub-cultured every two weeks until using.

\section{Screening kojic acid medium and inoculum preparation}

For the harvesting of Aspergillus spores the fungal isolates were re-cultured on the same preservation medium (PDA) at $28 \pm 1^{\circ} \mathrm{C}$ aerobically for 3 days (figure 1(a)). Aspergillus spores were collected off medium by scratching the growth surface and mixed with sterilized $0.1 \%(\mathrm{v} / \mathrm{v})$ tritonx 100 in deionized water, and vortex for $5 \mathrm{~min}$ then diluted with the same steps to $3 \times 10^{5} \mathrm{spore} / \mathrm{ml}$. Kojic acid screening medium includes $(\mathrm{g} / \mathrm{l})$ : glucose $100 ; \mathrm{KH}_{2} \mathrm{PO}_{4}, 1.0$; yeast extract, 5.0 $\mathrm{MgSO}_{4} .7 \mathrm{H}_{2} \mathrm{O}, 0.5$ and 1000 distilled water (Ariff et al., 1996; Liu et al., 2016; Mahmoud et al., 2019). Before sterilizing the medium by autoclaving ( $20 \mathrm{~min}$., 1.5 atmospheric pressure at $121^{\circ} \mathrm{C}$ ) initial $\mathrm{pH}$ was set to 3 by $1 \mathrm{~N} \mathrm{HCl}$. After sterilization, the medium was fortified with membrane sterilized $(0.22 \mathrm{~mm}$ pore size) chloramphenicol as bacteriostatic agent at $250 \mathrm{mg} / \mathrm{ml}$ (Ibrahim and Mahmoud, 2019). Each $100 \mathrm{~mL}$ medium inoculated with one $\mathrm{ml}$ contains $3 \times$ $10^{5}$ spore of Aspergillus inoculum prepared suspension stock, incubated aerobically at $28 \pm 1^{\circ} \mathrm{C}$ incubator with rotary shaker $(150 \mathrm{rpm})$ for 7 days. After that, culture flask filtered on weighed filter paper (Whatman No. 113), washed trice by distilled water and dried in hot air oven at $70{ }^{\circ} \mathrm{C}$ for $24 \mathrm{~h}$. to estimated Aspergillus dry (DM) mass. Supernatants were collected and centrifuged at $4,000 \times \mathrm{g}$ for $10 \mathrm{~min}$ then clear supernatants were used for quantitative estimation of KA (figure 1(b)) and the consumed sugars (CS).
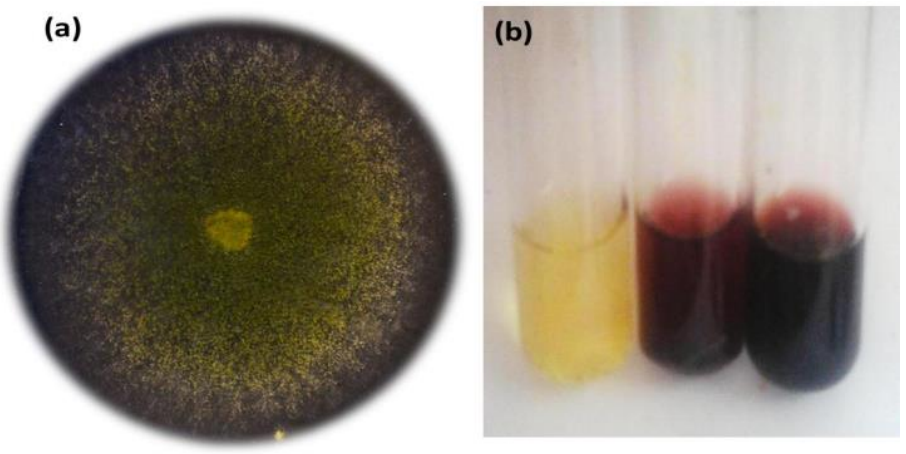

Figure 1 (a) growth of Aspergillus oryzae on PDA medium after three days, (b) purple-red color developed after the addition of ferric chloride reagents against kojic acid free samples (yellow).

\section{Selection of the most potent fungal isolate for safety test}

Aspergillus oryzae isolate number four was selected as the highest KA producer from the screening experiment and tested for its ability to produce mycotoxins especially aflatoxins as following; the fungus spore suspension was inoculated into liquid PDA medium and incubated for 10 days at $28 \pm 1^{\circ} \mathrm{C}$ in rotary shaker incubator with speed $150 \mathrm{rpm}$. After ten days culture flask were homogenized with equal volume of chloroform in high speed homogenizer for $5 \mathrm{~min}$., and then filtrated to remove the fungal mycelia. Organic chloroform layer was separated from aqueous layer using separation funnel on sodium sulfate anhydrous and being allowed to evaporate in order to concentrate it to approximately $1 \mathrm{ml}$ (Scott et al., 1970; Sadhasivam et al., 2017). Presence of aflatoxins in crude extract was detected using thin layer chromatography (TLC) as following; silica gel plates $\left(\mathrm{SiO}_{2}, 60 \mathrm{GF} 254\right)$ were injected with $10 \mu 1$ crude extract leave the spot to dry in cold air flow, placed in solvent chamber contains in chloroform: acetone at a ratio 90:10; as running solvents. After running step, the developed plates were dried in air and examined under shortwave $(254 \mathrm{~nm})$ and longwave (356 $\mathrm{nm}$ ) ultraviolet radiation. When aflatoxin is present, developed blue or green colours bands of aflatoxins will observed (Scott et al., 1970; El-Kady and Moubasher, 1982; Lin et al., 1998).

\section{Maximization of kojic acid production by RSM}

For maximizing kojic acid production central composite design (CCD) of response surface methodology (RSM) was utilized. The four production medium constituents including glucose, yeast extract, $\mathrm{KH}_{2} \mathrm{PO}_{4}$, and $\mathrm{MgSO}_{4} .7 \mathrm{H}_{2} \mathrm{O}$ were analyzed in five levels contains very low concentration (-2), low concentration ($1)$, the original constituent concentration $(0)$, and high concentration $(+1)$, higher concentration $(+2)$ as shown in table (1). A set of twenty four factorial runs in trice and one run represents the center point (for reproducibility) were performed (Yan et al., 2014; Nafady et al., 2015; Mahmoud et al., 2020b). The variables are following equation (1) for the statistical calculation:

$\mathrm{x}_{\mathrm{i}}=\mathrm{X}_{\mathrm{i}}-\mathrm{X}_{0} / \delta \mathrm{X}$

Where $\mathrm{X}_{\mathrm{i}}$ represents the dimensionless number of $\mathrm{X}_{\mathrm{i}}$ as independent variable; $\mathrm{X}$ represents the experimental value of the variable; $X_{0}$ represents the value of $X_{i}$ at the center point; $\delta \mathrm{X}$ represents the step change in variable $\mathrm{i}$ experimental numbers to a variation of a unit for dimensionless value of variable i. Each variable role, interactions, and statistical analysis to calculate the predicted values is calculated by applying the quadratic equation (2):

$\mathrm{Y}=\beta_{0}+\sum \beta_{\mathrm{i}} \mathrm{x}_{\mathrm{i}}+\sum \beta_{\mathrm{ii}} \mathrm{x}_{\mathrm{i}}^{2}+\sum \beta_{\mathrm{ij}} \mathrm{x}_{\mathrm{ij}}$

Where $\mathrm{Y}$ represents the predicted values, $\beta_{0}$ represents the offset term, $\beta$ represents the linear effect, $\beta_{\mathrm{ii}}$ represents the squared effect, $\beta_{\mathrm{ij}}$ is the interaction effect, $x_{i j}$ represents the independent variables levels. To confirm the selected optimized conditions Derringer's desired methodology was used; trice experiments were conducted under the previous cleared optimized conditions then compared the actual and predicted values for the validity of the models.

\section{Stability of Kojic acid at different temperatures}

The stability of kojic acid at different temperatures was determined as following Fermentation broth of the highest KA in the best optimized medium constituents was centrifuge at $4,000 \times \mathrm{g}$ for $5 \mathrm{~min}$. to remove any fungal residuals and used. At the beginning of the experiment the crude KA quantity was measured as initial concentrations. Glass tubes containing five $\mathrm{ml}$ of the aqueous KA broth were incubated in water bath at $40,60,80$, and $100^{\circ} \mathrm{C}$, samples periodically withdrawn during the incubation period at $0,1,2,3,4$, and $5 \mathrm{~h}$. Changing in KA concentration was measured spectrophotometerically at $500 \mathrm{~nm}$ using ferrous chloride reagent. The degradation ratio calculated as the ratio between KA at zero time and after the treatment. All treatments were in triplicate and the standard deviations were estimated (Santos-Edinum et al., 2013).

\section{Chemical analysis}

Spectrophotometer measurements analysis was estimated using a T60 split beam UV spectrophotometer covering the wavelength range of 190-1100 nm. Kojic acid was determined as Bentley (1957) and (2006) by ferric chloride (1\% in $0.1 \mathrm{~N} \mathrm{HCl}$ ) reagent, purple-red color will developed and measured against free blank quantitatively at $500 \mathrm{~nm}$. Kojic acid concentrations were calculated from absorbance using standard curve of pure kojic acid as g/l (Mahmoud at $\boldsymbol{e l}$., 2020a). Residual sugars were measured using anthrone-sulfuric acid method as decribed by Yemm and Willis $\mathbf{( 1 9 5 4 )}$ by reacting anthrone-sulfuric acid reagen with the fungal supernatant at $100^{\circ} \mathrm{C}$ in water bath for ten minutes. After cooling, the absorbance of developed green color was detected at $620 \mathrm{~nm}$ against free sample, then the glucose concentration was calculated from standard glucose curve $(\mathrm{g} / \mathrm{l})$.

\section{Statistical analysis}

Statistical analysis was done using the statistical software of statistical program Design Expert 7.0.0 (Minneapolis, Stat-Ease Inc., USA). Analyses of experimental data were performed using multiple regression analysis. Linear, quadratic regression coefficients and the interaction that involved in the design model were analysis by analysis of variance (ANOVA). The quality of the regression model was expressed as $R^{2}$, runs significance checked by $F$ - test with probability ranges $(\mathrm{p} \leq 0.05)$. To clear the variables relationships and the optimum variables concentrations, response surface $(3 \mathrm{D})$ plots and curves were drawn.

\section{RESULTS}

Screening for kojic acid production and selection of the most potent fungal isolates

Ten isolates of Aspergillus flavus group including four isolates of A. flavus and six isolates of $A$. oryzae were isolated from different sources air, soil, milk, and spoiled nuts and tested for kojic acid production on glucose medium (figure 2). All isolates were positive to KA production with wide quantities range from $0.091 \pm 0.01 \mathrm{~g} / 1$ (A. flavus no.9) to $66.81 \pm 0.95 \mathrm{~g} / 1$ (A. oryzae no. 4). The isolates 
also give various mass of growth between $18.13 \pm 0.34 \mathrm{~g} / 1$ (A. oryzae no. 3 ) and $37.3 \pm 0.71 \mathrm{~g} / 1$ (A. oryzae no. 1) with sugar consumption percentage from $27.58 \pm 1.45 \%$ (A. flavus no.9) to $90.175 \pm 1.13 \%$ (A. oryzae no. 4). Aspergillus oryzae (Ao-4) isolate was selected as the most kojic acid potent isolate giving $66.81 \pm 0.95 \mathrm{~g} / 1$ with $21.6 \pm 0.65 \mathrm{~g} / 1$ dry mass and highest sugar consumption percentage $90.175 \pm 1.13 \%$ comparing to the other isolates. Mycotoxins analysis gives negative results, no aflatoxin bands appeared, which combine the isolate as safe industrial potential isolate. Brief morphology (macroscopic and microscopic) description of the selected isolate was cleared in figure (3). Aspergillus oryzae grown on Czapek's dextrose agar medium (CzD) and Potato dextrose agar medium (PDA) appeared as yellowish margins shifting to yellow-green towards the colony center when it young ( 3 days) shifting to greyed-brown when it became old. The developing colony lacks exudates with colorless reverse. Microscopic features includes colorless long conidiophores 15-25 $\mu \mathrm{m}$, large radiate conidial head with sub-globose vesicle $(18-45 \mu \mathrm{m})$ without metulae, conidial chains with globose to sub-globose, smooth to rough conidia 4-6 $\mu \mathrm{m}$ diameter.

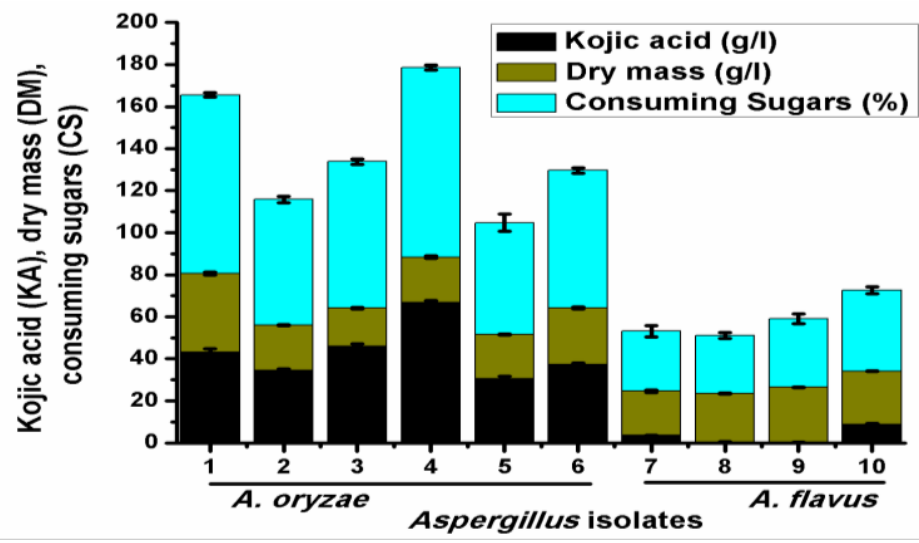

Figure 2 Screening for kojic acid production $(\mathrm{g} / \mathrm{l})$, dry mass $(\mathrm{g} / \mathrm{l})$ and sugar consumption (\%) by ten isolates of Aspergillus (numbered 1-10) on kojic acid production medium.

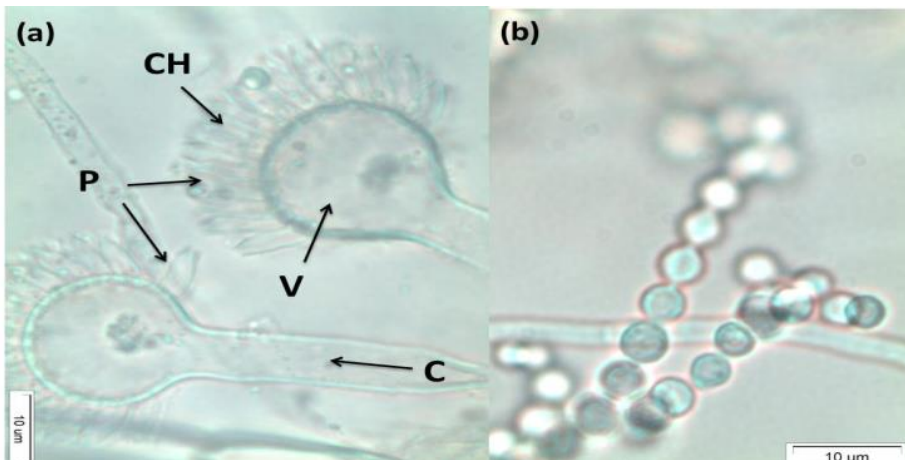

Figure 3 Aspergillus oryzae (Ahlburg) Cohn microscopic features, includes (a) conidial head $(\mathrm{CH})$, phialid $(\mathrm{P})$, conidiophore $(\mathrm{C})$, vesicle $(\mathrm{V})$ in the left figure and (b) conidial chains in the write figure, Bars, $10 \mu \mathrm{m}$.

\section{Maximization of kojic acid production by RSM}

For maximizing kojic acid production statistical optimization using CCD design of response surface methodology was performed on medium containing four constituents (glucose, yeast extract, $\mathrm{KH}_{2} \mathrm{PO}_{4}$, and $\mathrm{MgSO}_{4} .7 \mathrm{H}_{2} \mathrm{O}$ ) at five levels ($2,-1,0,+1,+2)$ as mentioned in table (1). Predicted values of the estimated runs calculated by applying multiple regression analysis using second-order polynomial equation (2). Kojic acid predicted values calculated by equation (3), dry mass (g/l) by equation (4) and sugar consumption (\%) by equation (5) as following:

Kojic acid $(\mathrm{g} / \mathrm{l})=68.14+22.29 * \mathrm{~A}+15.59 * \mathrm{~B}+7.42 * \mathrm{C}+6.5 * \mathrm{D}+10.10 * \mathrm{AB}$ $+7.08 * \mathrm{AC}+5.44 * \mathrm{AD}+4.18^{*} \mathrm{BC}+0.0139 * \mathrm{BD}+3.37 * \mathrm{CD}+(-6.26)^{*} \mathrm{~A}^{2}+$ $(-2.58) * \mathrm{~B}^{2}+(-6.54) * \mathrm{C}^{2}+(-4.03) * \mathrm{D}^{2}$

Dry mass $(\mathrm{g} / \mathrm{l})=26.47+13.07 * \mathrm{~A}+(-7.31) * \mathrm{~B}+1.71 * \mathrm{C}+0.41 * \mathrm{D}+(-3.9) *$ $\mathrm{AB}+0.82 * \mathrm{AC}+0.66 * \mathrm{AD}+(-4.46) * \mathrm{BC}+1.4 * \mathrm{BD}+0.06 * \mathrm{CD}+0.77 * \mathrm{~A}^{2}+$ $0.44 * \mathrm{~B}^{2}+1.63 * \mathrm{C}^{2}+(-0.026) * \mathrm{D}^{2}$

(4)

Sugar consumption $(\%)=93.02+(-11.74) * \mathrm{~A}+8.29 * \mathrm{~B}+6.04 * \mathrm{C}+6.19 * \mathrm{D}+$ $1.05 * \mathrm{AB}+2.86 * \mathrm{AC}+0.26 * \mathrm{AD}+(-1.16) * \mathrm{BC}+0.37 * \mathrm{BD}+2.33 * \mathrm{CD}+($ $8.57) * A^{2}+(-5.04) * B^{2}+(-5.7) * C^{2}+(-8.02) * D^{2}$

Where $\mathrm{A}, \mathrm{B}, \mathrm{C}, \mathrm{D}$ are the coded values of glucose, yeast extract, $\mathrm{KH}_{2} \mathrm{PO}_{4}$, and $\mathrm{MgSO}_{4} .7 \mathrm{H}_{2} \mathrm{O}$, respectively. Maximum experimental value of kojic acid was $139.24 \mathrm{~g} / \mathrm{L}$, whereas the predicted corresponding value was $135.8 \mathrm{~g} / \mathrm{L}$ using glucose $(+1 ; 200 \mathrm{~g} / \mathrm{l})$, yeast extract $(+1 ; 6 \mathrm{~g} / \mathrm{l}), \mathrm{KH}_{2} \mathrm{PO}_{4},(+1 ; 1.5 \mathrm{~g} / \mathrm{l})$ and $\mathrm{MgSO}_{4} .7 \mathrm{H}_{2} \mathrm{O}(+1 ; 1 \mathrm{~g} / \mathrm{l})$ through run (24) with $33.47 \mathrm{~g} / 1$ dry mass and $82.25 \%$ sugar consumption. Maximum experimental value of dry mass was $63.33 \mathrm{~g} / \mathrm{l}$, with corresponding predicted value $62.16 \mathrm{~g} / \mathrm{L}$ using glucose $(+1 ; 200 \mathrm{~g} / \mathrm{l})$, yeast extract $(-1 ; 4 \mathrm{~g} / \mathrm{l}), \mathrm{KH}_{2} \mathrm{PO}_{4},(+1 ; 1.5 \mathrm{~g} / \mathrm{l})$ and $\mathrm{MgSO}_{4} .7 \mathrm{H}_{2} \mathrm{O}(-1 ; 0.1 \mathrm{~g} / \mathrm{l})$ through run (13). Highest sugar consumption percentage observed in run (2) with experimental value $94.15 \%$ and predicted $95.31 \%$ using glucose $(-1 ; 50 \mathrm{~g} / \mathrm{l})$, yeast extract $(+1 ; 1.5 \mathrm{~g} / \mathrm{l}), \mathrm{KH}_{2} \mathrm{PO}_{4},(+1 ; 1.5 \mathrm{~g} / \mathrm{l})$ and $\mathrm{MgSO}_{4} .7 \mathrm{H}_{2} \mathrm{O}(+1 ; 1 \mathrm{~g} / \mathrm{l})$ as cleared in in table (1).

(a)

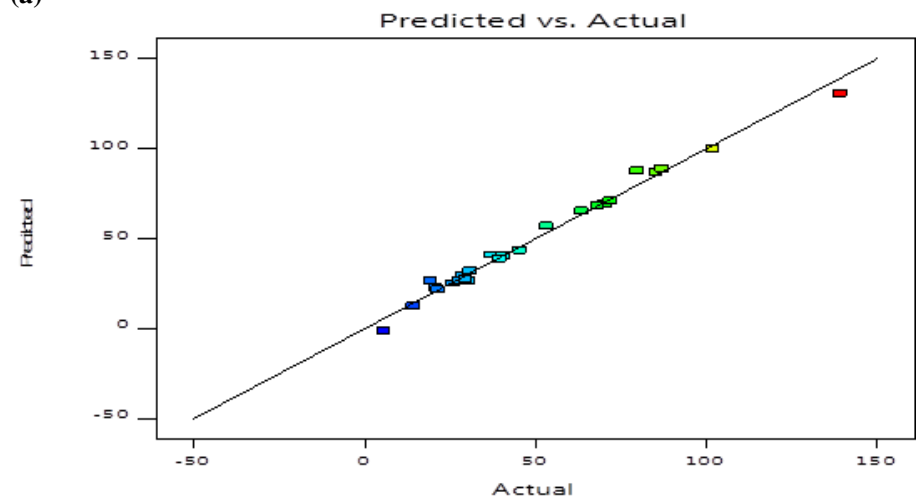

(b)

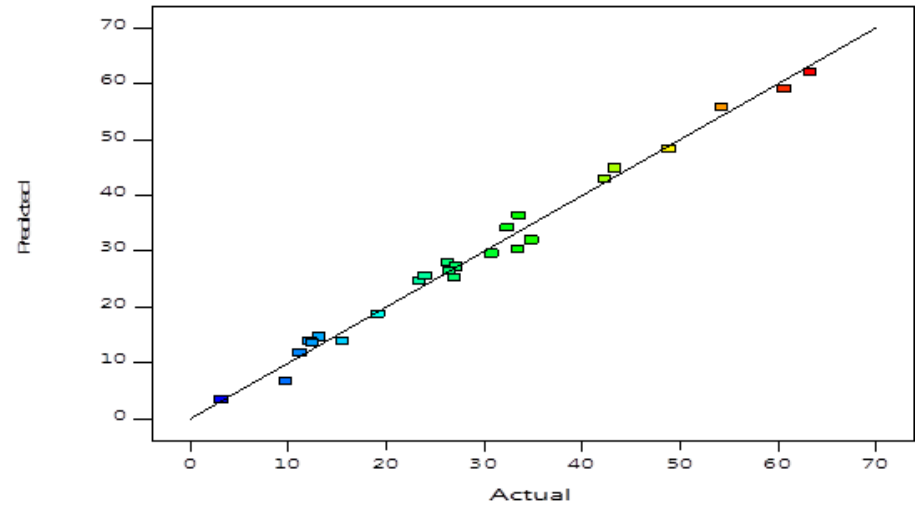

(c)
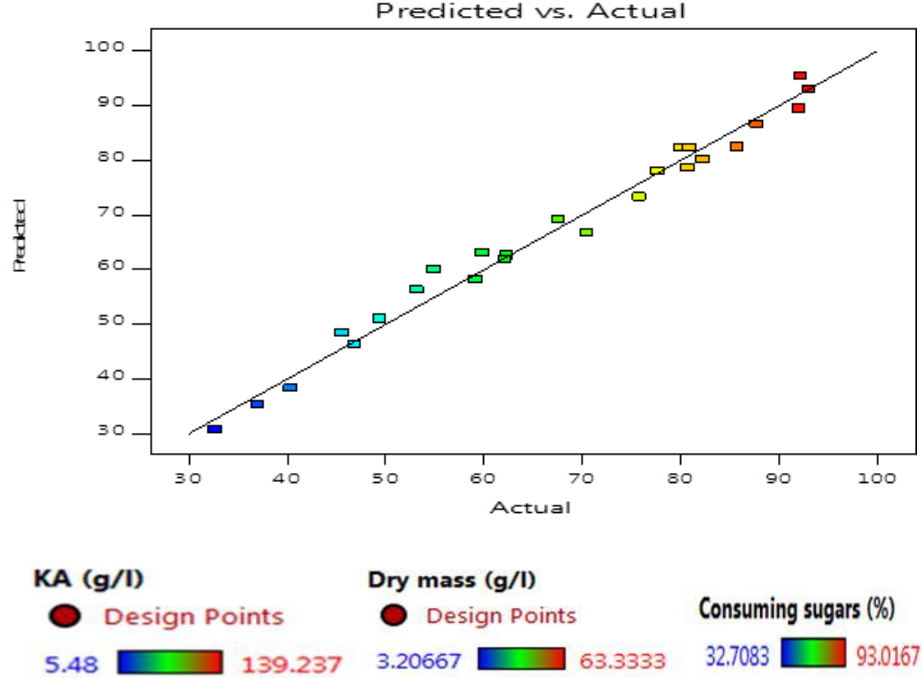

Figure 4 Comparison between the predicted and the actual values of kojic acid production (a), dry mass (b), and consuming sugars (c) by Aspergillus oryzae (Ahlburg) Cohn.

The predicted values of KA, DM, and CS of the response surface model were located in close proximity to the experimental ones as shown in Table 1 and figures (4a for KA, $\mathbf{4 b}$ for DM, and $\mathbf{4 c}$ for CS) which supported the consideration of RSM optimizing method is sufficient to illustrate and explain data variations and variables actual relationships. These polynomial Eqs $(\mathbf{3}, \mathbf{4}$, and 5) was further tested for confirmation the model suitability and significance by an analysis of variance (ANOVA) as shown in table 2 . The model $F$ and $P$ values of kojic acid $(54.1 ; \mathrm{P}<0.0001)$, dry mass $(64 ; \mathrm{P}<0.0001)$, and consuming sugars $(41.63 ; \mathrm{P}<0.0001)$. The test estimated the model failure of represent data 
in the experimental values at points by lack of fit significance that preferred nonsignificant for the model signify. Lack of fit values was no significant relative to the pure error (lack of fit $\mathrm{P}<0.0001$ ) proved that the model was significant. To evaluate the model goodness and fitting, different evaluated statistical parameters like coefficient $\left(R^{2}\right)$ estimation was calculated, $R^{2}$ values of KA was 0.987, DM 0.989 and CS 0.9831 with adjusted $R^{2}$ values were $0.9687,0.9735$ and 0.9595 for $\mathrm{KA}, \mathrm{DM}$ and $\mathrm{CS}$, respectively which indicates that the entire variation was explained by the model.

Table 1 Response surface experimental design with operational variables; glucose (A), yeast extract $(\mathrm{B}), \mathrm{KH}_{2} \mathrm{PO}_{4}(\mathrm{C})$, and $\mathrm{MgSO}_{4} .7 \mathrm{H}_{2} \mathrm{O}(\mathrm{D})$, actual and predicted responses; kojic acid yield (KA; g/l), dry mass (DM; g/l), and consuming sugars (CS; \%).

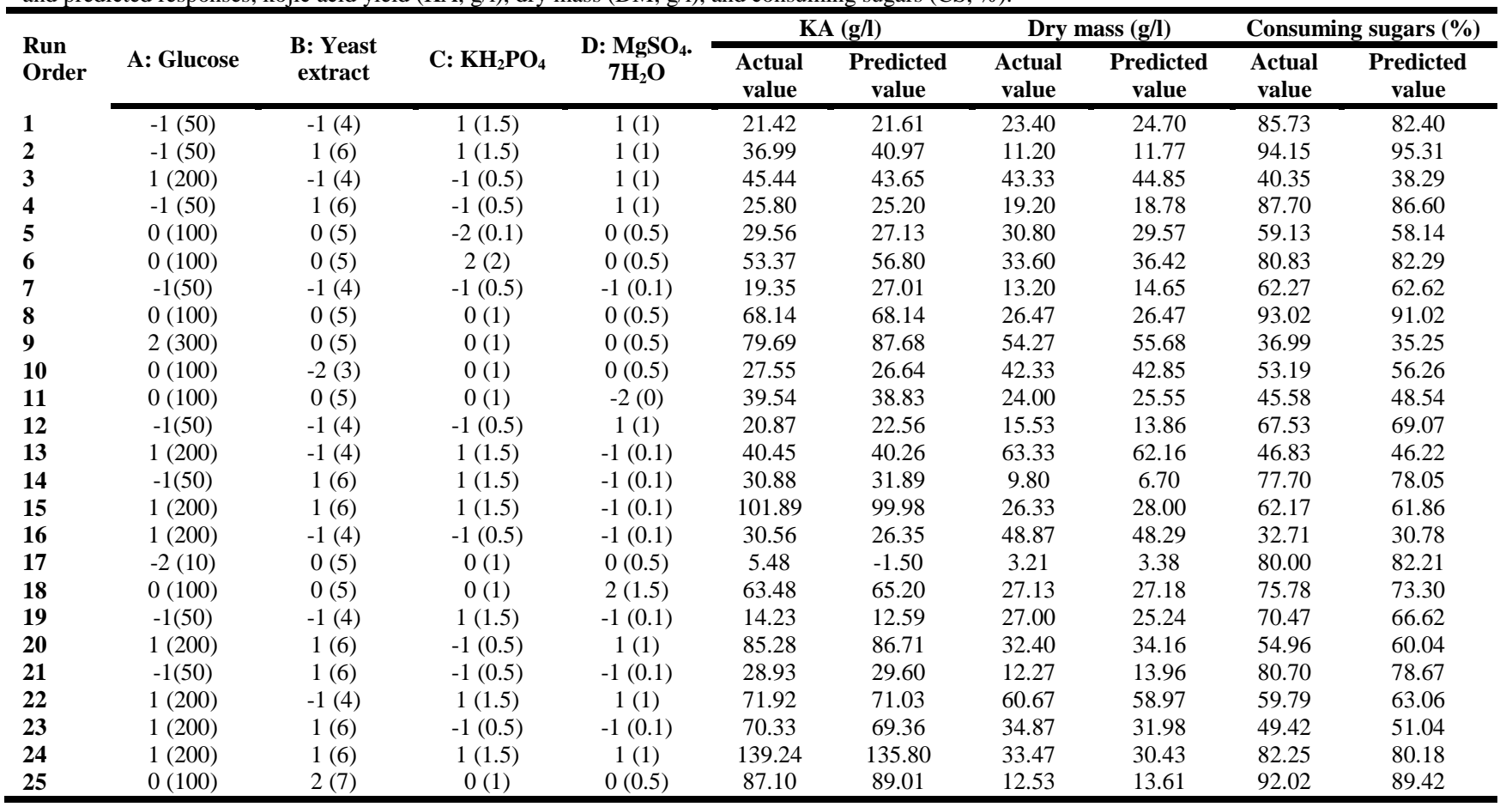

Table 2 Analysis of variance (ANOVA) for response surface (RSM) quadratic model of kojic acid (KA; g/l), dry mass (DM; g/l) and consuming sugars (CS; \%) by Aspergillus oryzae.

\begin{tabular}{|c|c|c|c|c|c|c|c|c|c|c|c|c|c|}
\hline \multirow[b]{2}{*}{ Source } & \multicolumn{3}{|c|}{ Sum of Squares } & \multicolumn{4}{|c|}{ Mean Square } & \multicolumn{3}{|c|}{$F$-value } & \multicolumn{3}{|c|}{$p$-value } \\
\hline & KA (g/l) & $\begin{array}{l}\text { DM } \\
(\mathrm{g} / \mathrm{l})\end{array}$ & CS $(\%)$ & df & $\mathbf{K A}(\mathbf{g} / \mathbf{l})$ & $\begin{array}{l}\text { DM } \\
(\mathrm{g} / \mathrm{l})\end{array}$ & $\operatorname{CS}(\%)$ & $\begin{array}{c}\text { KA } \\
(\mathrm{g} / \mathbf{l})\end{array}$ & $\begin{array}{l}\text { DM } \\
(\mathrm{g} / \mathrm{l})\end{array}$ & $\begin{array}{c}\text { CS } \\
(\%)\end{array}$ & $\mathbf{K A}(\mathrm{g} / \mathrm{l})$ & DM (g/l) & $\operatorname{CS}(\%)$ \\
\hline Model & 24200.06 & 6125.46 & 8017.15 & 14 & 1728.58 & 437.53 & 572.65 & 54.10 & 64.00 & 41.63 & $<0.0001$ & $<0.0001$ & $<0.0001$ \\
\hline A-Glucose & 11928.75 & 4102.59 & 3308.66 & 1 & 11928.75 & 4102.59 & 3308.66 & 373.32 & 600.11 & 240.50 & $<0.0001$ & $<0.0001$ & $<0.0001$ \\
\hline B-Yeast extract & 5833.56 & 1281.88 & 1650.28 & 1 & 5833.56 & 1281.88 & 1650.28 & 182.57 & 187.51 & 119.96 & $<0.0001$ & $<0.0001$ & $<0.0001$ \\
\hline $\mathrm{C}-\mathrm{KH}_{2} \mathrm{PO}_{4}$ & 1321.20 & 70.50 & 874.60 & 1 & 1321.20 & 70.50 & 874.60 & 41.35 & 10.31 & 63.57 & $<0.0001$ & 0.0093 & $<0.0001$ \\
\hline D-MgSO ${ }_{4} \cdot 7 \mathrm{H}_{2} \mathrm{O}$ & 1043.10 & 4.00 & 920.15 & 1 & 1043.10 & 4.00 & 920.15 & 32.64 & 0.5853 & 66.88 & 0.0002 & 0.4619 & $<0.0001$ \\
\hline $\mathbf{A B}$ & 1633.36 & 243.88 & 17.77 & 1 & 1633.36 & 243.88 & 17.77 & 51.12 & 35.67 & 1.29 & $<0.0001$ & 0.0001 & 0.2823 \\
\hline $\mathbf{A C}$ & 802.28 & 10.78 & 130.88 & 1 & 802.28 & 10.78 & 130.88 & 25.11 & 1.58 & 9.51 & 0.0005 & 0.2378 & 0.0116 \\
\hline AD & 472.77 & 7.02 & 1.12 & 1 & 472.77 & 7.02 & 1.12 & 14.80 & 1.03 & 0.0815 & 0.0032 & 0.3347 & 0.7811 \\
\hline BC & 279.41 & 318.62 & 21.35 & 1 & 279.41 & 318.62 & 21.35 & 8.74 & 46.61 & 1.55 & 0.0144 & $<0.0001$ & 0.2413 \\
\hline BD & 0.0031 & 31.55 & 2.21 & 1 & 0.0031 & 31.55 & 2.21 & 0.0001 & 4.61 & 0.1605 & 0.9924 & 0.0572 & 0.6971 \\
\hline CD & 181.46 & 0.0625 & 87.01 & 1 & 181.46 & 0.0625 & 87.01 & 5.68 & 0.0091 & 6.32 & 0.0384 & 0.9257 & 0.0307 \\
\hline $\mathbf{A}^{2}$ & 443.05 & 6.64 & 829.72 & 1 & 443.05 & 6.64 & 829.72 & 13.87 & 0.9711 & 60.31 & 0.0040 & 0.3477 & $<0.0001$ \\
\hline $\mathbf{B}^{2}$ & 75.11 & 2.19 & 287.35 & 1 & 75.11 & 2.19 & 287.35 & 2.35 & 0.3210 & 20.89 & 0.1562 & 0.5835 & 0.0010 \\
\hline $\mathrm{C}^{2}$ & 483.64 & 30.10 & 366.99 & 1 & 483.64 & 30.10 & 366.99 & 15.14 & 4.40 & 26.68 & 0.0030 & 0.0623 & 0.0004 \\
\hline $\mathbf{D}^{2}$ & 183.54 & 0.0075 & 727.22 & 1 & 183.54 & 0.0075 & 727.22 & 5.74 & 0.0011 & 52.86 & 0.0375 & 0.9742 & $<0.0001$ \\
\hline
\end{tabular}

The significance of individual variables and interactions cleared in table (2) as the ANOVA results. Individual variables glucose (A), and yeast extract (B) were significant $(\mathrm{P}<0.0001)$ in their effects on kojic acid production, dry mass and consuming sugar, while $\mathrm{KH}_{2} \mathrm{PO}_{4}(\mathrm{C})$ ( $P$ 0.0093), and $\mathrm{MgSO}_{4} .7 \mathrm{H}_{2} \mathrm{O}$ (D) $(P$ $0.4619)$ were non-significant for dry mass. Interaction between variables found to be non-significant $(\mathrm{P}>0.0001)$ for $\mathrm{BC}$ (yeast extract; $\mathrm{KH}_{2} \mathrm{PO}_{4}$ ) and $\mathrm{BD}$ (yeast extract; $\mathrm{MgSO}_{4} .7 \mathrm{H}_{2} \mathrm{O}$ ) in kojic acid production; $\mathrm{AC}$ (glucose; $\mathrm{KH}_{2} \mathrm{PO}_{4}$ ), $\mathrm{AD}$ (glucose; $\mathrm{MgSO}_{4} .7 \mathrm{H}_{2} \mathrm{O}$ ), $\mathrm{BD}$ (yeast extract; $\left.\mathrm{MgSO}_{4} .7 \mathrm{H}_{2} \mathrm{O}\right), \mathrm{CD}\left(\mathrm{KH}_{2} \mathrm{PO}_{4}\right.$; $\mathrm{MgSO}_{4} .7 \mathrm{H}_{2} \mathrm{O}$ ) for dry mass and for consuming sugars the interaction between variables was not-significant. Response surface plots and contour plots can be used for the $3 \mathrm{D}$ visualization of the interaction between the pair-wise of the four factors selected, when the other two factors are constant as cleared in figure (5) explaining the effect of A; glucose; B: yeast extract; $\mathrm{C}$ : $\mathrm{KH}_{2} \mathrm{PO}_{4} ; \mathrm{D}$ : $\mathrm{MgSO}_{4} .7 \mathrm{H}_{2} \mathrm{O}$ on kojic acid production (a), dry mass (b), and consuming sugars (c) by Aspergillus oryzae (Ahlburg) Cohn. The interaction between AB (glucose; yeast extract), $\mathrm{AC}$ (glucose; $\left.\mathrm{KH}_{2} \mathrm{PO}_{4}\right)$, and $\mathrm{CD}\left(\mathrm{KH}_{2} \mathrm{PO}_{4} ; \mathrm{MgSO}_{4} .7 \mathrm{H}_{2} \mathrm{O}\right)$ was drawn for kojic acid production $(\mathrm{g} / \mathrm{l})$ pictures $5(\mathbf{a 1}, \mathbf{a 2}, \mathbf{a 3})$; $\mathrm{AB}$ (glucose; yeas extract), $\mathrm{AC}$ (glucose; $\mathrm{KH}_{2} \mathrm{PO}_{4}$ ), and $\mathrm{BC}$ (yeast extract; $\mathrm{KH}_{2} \mathrm{PO}_{4}$ ) for dry mass $(\mathrm{g} / \mathrm{l})$ pictures 5(b1, b2, b3) and $\mathrm{AB}$ (glucose; yeast extract), $\mathrm{AC}$ (glucose; $\mathrm{KH}_{2} \mathrm{PO}_{4}$ ), and $\mathrm{BD}$ (yeast extract; $\mathrm{MgSO}_{4} \cdot 7 \mathrm{H}_{2} \mathrm{O}$ ) for consuming sugars (\%) pictures 5 (c1, c2, c3).

(a1) 
$\frac{g}{3}$

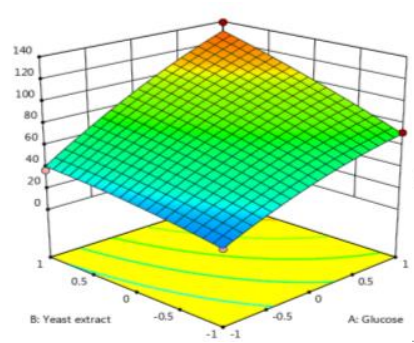

(a2)

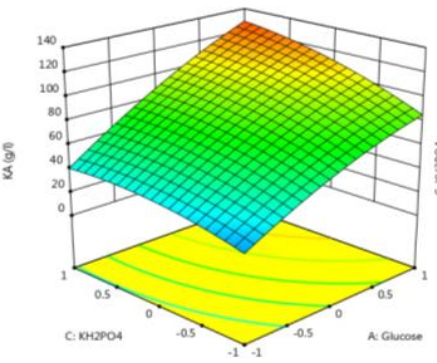

(a3)

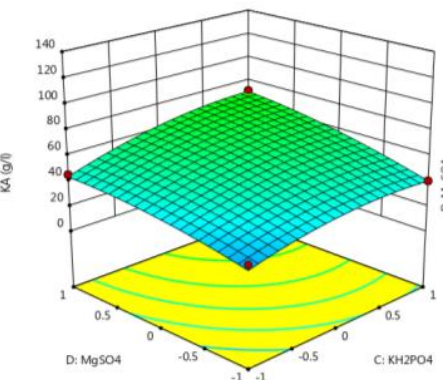

(b1)

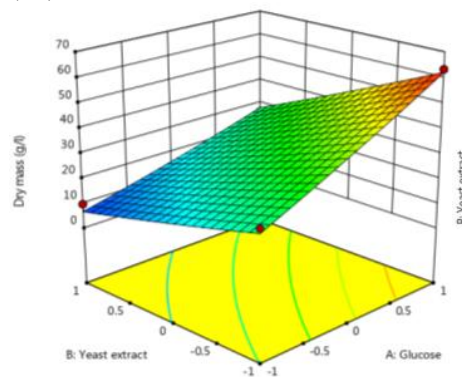

(b2)

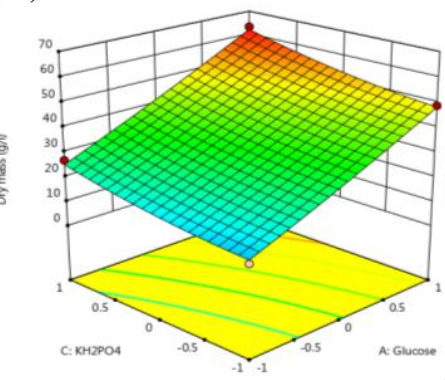

(b3)

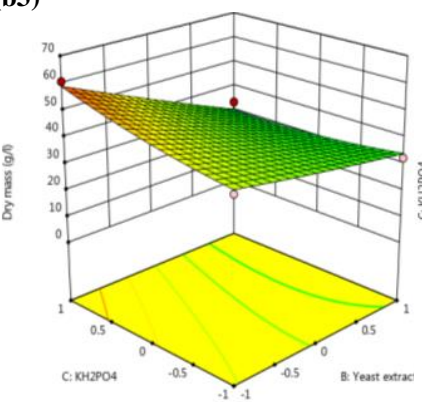

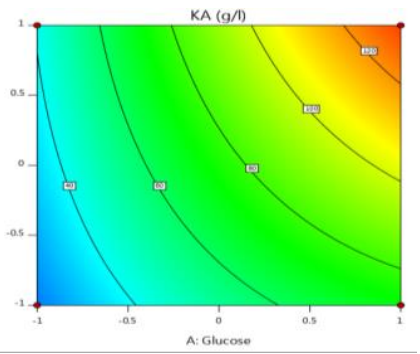
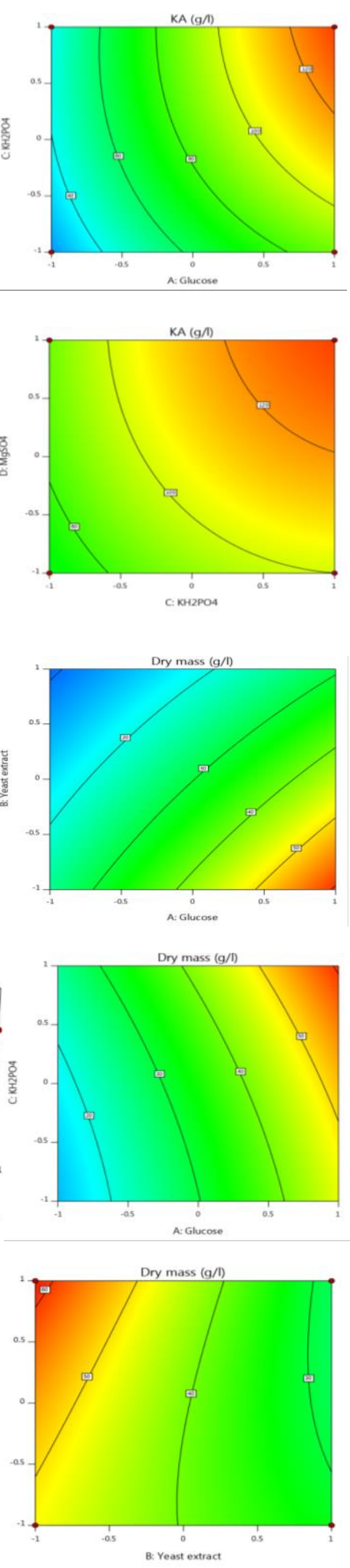
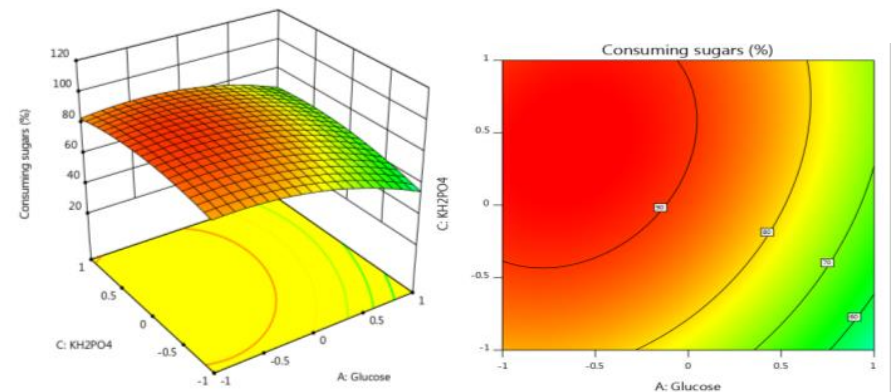

(c2)
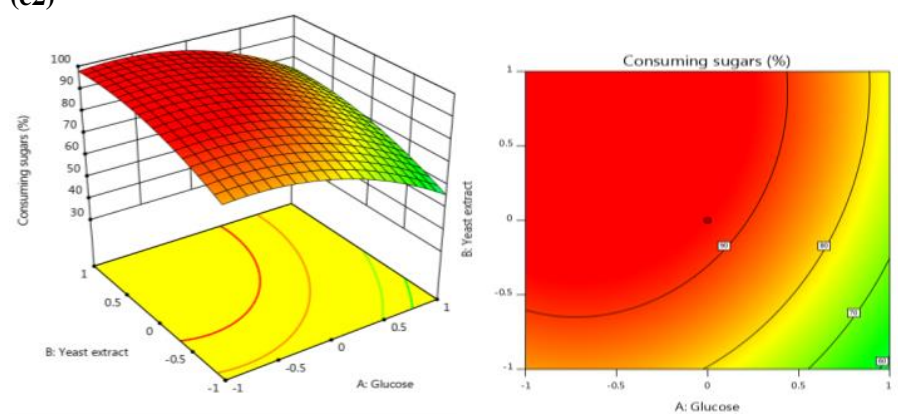

(c3)
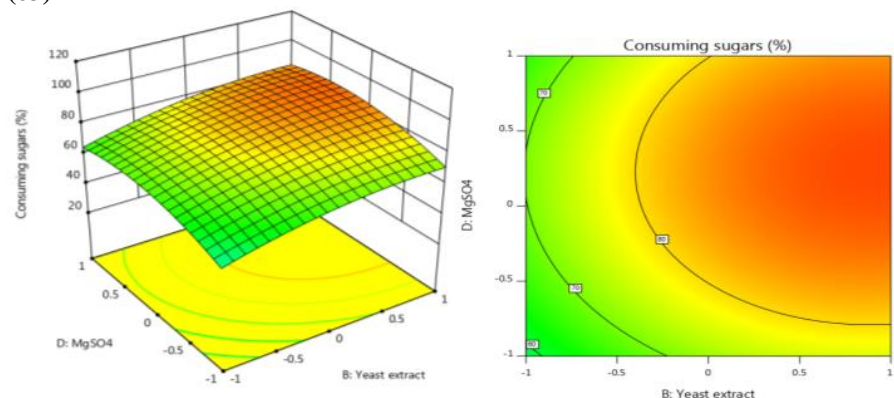

Figure $53 \mathrm{D}$ plots and contour plots of response surface design explaining the effect of A; glucose; B: yeast extract; $\mathrm{C}$ : $\mathrm{KH}_{2} \mathrm{PO}_{4} ; \mathrm{D}: \mathrm{MgSO}_{4} .7 \mathrm{H}_{2} \mathrm{O}$ on kojic acid production (a), dry mass (b), and consuming sugars (c) by Aspergillus oryzae (Ahlburg) Cohn

\section{Derringer's desirability function for model validation}

Previous results showed the different treatment (25 runs) that has effects on the three responses (KA, DM, and CS), however it was necessary to define the totally most desirable concentrations of the medium constituents. Optima treatments for high kojic acid production were estimated by application the Derringer's desirability function which combines variable levels that jointly maximize the target response. By applying this function methodology, the optimum levels of the various parameters were glucose $(1 ; 200 \mathrm{~g} / \mathrm{l})$, yeast extract $(1 ; 6 \mathrm{~g} / \mathrm{l}), \mathrm{KH}_{2} \mathrm{PO}_{4}$ $(1 ; 1.5 \mathrm{~g} / \mathrm{l})$, and $\mathrm{MgSO}_{4} \cdot 7 \mathrm{H}_{2} \mathrm{O}(1 ; 1 \mathrm{~g} / \mathrm{l})$, which gives $130.801 \mathrm{~g} / \mathrm{l}$ predicted kojic acid, $31 \mathrm{~g} / 1$ dry mass, and $87.22 \%$ sugar consumption with overall value of desirability 0.937 (Figure 6). For model validation, triplicate experiments performed under the same above-mentioned optima conditions and the mean values confront with predicted values, actual values were in agreement with predicted values with standard error \pm 4.2 using desirability functions that indicating the sufficiency of quadratic model developed. 

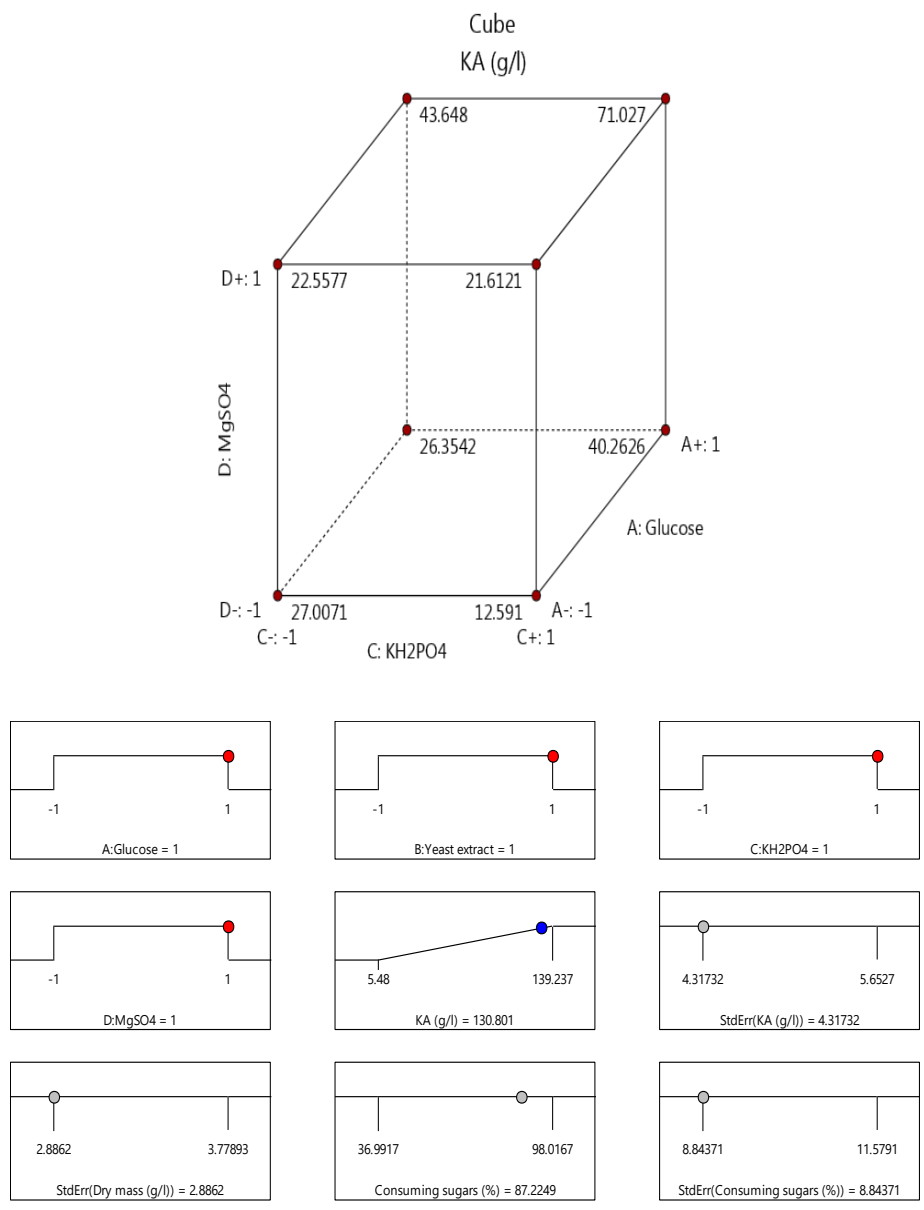

Desirability $=0.937$

Figure 6 Optimization desirability ramp plot for kojic acid production by Aspergillus oryzae

Stability of Kojic acid at different temperatures

Microbial kojic acid stability represents a significant factor that influence on its industrial application, extraction and purification strategies. Therefore, the stability of kojic acid against different heat stress $\left(40^{\circ} \mathrm{C}, 60^{\circ} \mathrm{C}, 80^{\circ} \mathrm{C}\right.$, and $\left.100^{\circ} \mathrm{C}\right)$ during five hours $(0,1,2,3,4$, and 5 h.) has been estimated as shown in figure (7). Overall, kojic acid preserve its stability in the first hour for all tested temperatures (slight changes at $100^{\circ} \mathrm{C}$ ), then start to change with percentage related to each specific temperature. At $40^{\circ} \mathrm{C}$, KA preserved its stability during the five hours from $136.36 \mathrm{~g} / \mathrm{K} \mathrm{KA}$ at zero time to $134.45 \mathrm{~g} / \mathrm{l} \mathrm{KA}$ after $5 \mathrm{~h}$.; at $60^{\circ} \mathrm{C}$, KA stability change slightly during the five hours from $136.36 \mathrm{~g} / 1 \mathrm{KA}$ at zero time to $127.05 \mathrm{~g} / 1 \mathrm{KA}$ after $5 \mathrm{~h}$.; at $80^{\circ} \mathrm{C}$, KA stability decreased during the five hours from $136.36 \mathrm{~g} / 1 \mathrm{KA}$ at zero time to $104.32 \mathrm{~g} / 1 \mathrm{KA}$ after $5 \mathrm{~h}$. At $100^{\circ} \mathrm{C}$, KA stability decreased especially after two hours from $136.36 \mathrm{~g} / \mathrm{l} \mathrm{KA}$ at zero time to $90.59 \mathrm{~g} / \mathrm{l} \mathrm{KA}$ with $33.6 \%$ reduction after $5 \mathrm{~h}$.

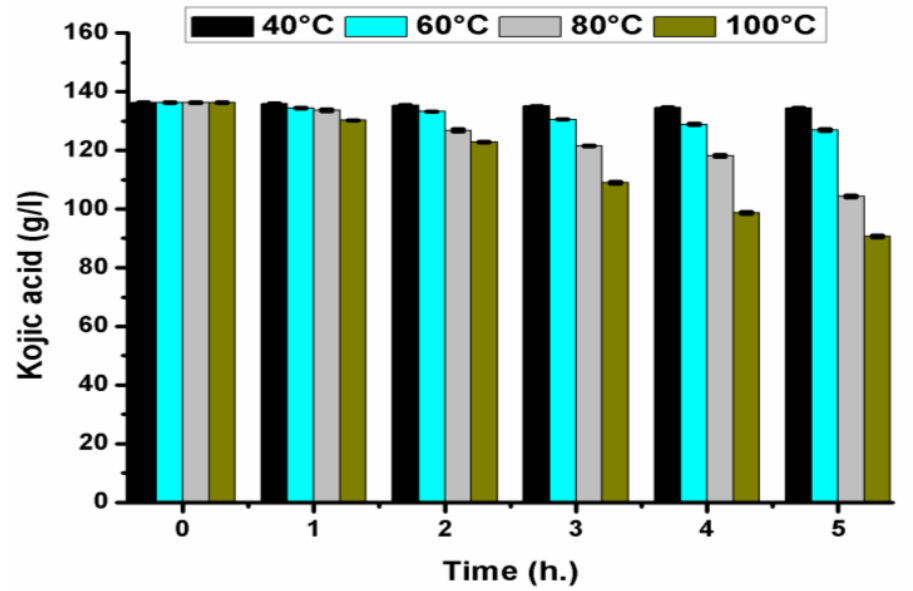

Figure 7 Stability of optimized kojic acid (g/l) produced by Aspergillus oryzae under different temperature degrees $\left(40^{\circ} \mathrm{C}, 60^{\circ} \mathrm{C}, 80^{\circ} \mathrm{C}\right.$, and $\left.100^{\circ} \mathrm{C}\right)$ after $0,1,2$, 3,4 , and 5 hours.

\section{DISCUSSION}

Kojic acid acts as remarkable heterocyclic natural secondary metabolite of Aspergillus with various hot spot applications in cosmetics products of skinlightning cosmetics (Wang et al., 2014), prevent hyper-pigmentation and skin wrinkling (Briganti et al., 2003), antibacterial, anti-inflammatory, anti-aging, antidermatophytic, and biocompatibility medical (Gonçalez et al., 2015; Syamsul $\boldsymbol{e t}$ al., 2017). Also, it used as pesticides, insecticidal agent (Burnett $\boldsymbol{e t}$ al., 2010), and food antioxidant agent (Sheikhshoaie et al., 2017). Microbial kojic acid concentrated highly on Aspergillus species especially Aspergillus flavus group. Aspergillus clavatus, A fumigatus, A candidus, A awamorii, A. flavus, A. oryzae, A. parasiticus, and A. tamarii produced kojic acid (Kwak and Rhee, 1992; Terabayashi et al., 2010; Chang et al., 2011).

Ten isolates of A. flavus and A. oryzae isolated from various Egyptian sources were producible of KA in range $0.091 \pm 0.01$ to $66.81 \pm 0.95 \mathrm{~g} / \mathrm{l}$. In agreement with our screening data; Manabe et al. (1981) recorded that A. flavus could produce 40 g/L KA after optimization, Kwak and Rhee (1991) obtained 80 g/l KA from immobilized $A$. oryzae cells, El-Sharkawy (1995) obtained $60 \mathrm{~g} / \mathrm{l} \mathrm{KA}$ by $A$ flavus ATCC 9179 using immobilization, Ogawa et al. (1995) obtained 20g/L KA by A. oryzae NRRL 484, Wakisaka et al. (1998) obtained 24 g/L KA from A. oryzae. Liu et al. (2016) obtained $83.47 \mathrm{~g} / \mathrm{L}$ KA by Aspergillus oryzae after several optimization processes. Mahmoud at el. (2020a) recorded $26.63 \pm 0.04$ g/l KA using zinc complexes as stimulator from Aspergillus flavus. Using Aspergillus flavus strains in the industrial production of kojic acid put producers and researcher's in critical situation regarding the risk of aflatoxin production by this isolates, however some researchers belived that if the isolate has the ability to produce aflatoxin, using a suitable medium and culture conditions for KA production could inhibit the aflatoxin synthesis (Basappa et al., 1970; Madihah et al., 1996). Utilization of safe isolates of Aspergillus species for kojic acid production, avoiding us critical issues regarding how to inhibit these toxins. Aspergillus oryzae (Ao-4) that give maximum production was selected as nontoxinogenic safe isolate for optimizing the production by five levels CCD design of RSM. According to several researchers not all kojic acid producers are toxinogenic, several kojic acid producers are non-aflatoxin synthesizers (Basappa, 1970; Madihah et al., 1996; Bracarense and Takayashi, 2014).

Maximum value of kojic acid with $108.4 \%$ increasing was $139.24 \mathrm{~g} / \mathrm{L}$ (predicted $135.8 \mathrm{~g} / \mathrm{L})$ using glucose $(+1 ; 200 \mathrm{~g} / \mathrm{l})$, yeast extract $(+1 ; 6 \mathrm{~g} / 1), \mathrm{KH}_{2} \mathrm{PO}_{4},(+1 ; 1.5$ $\mathrm{g} / \mathrm{l})$ and $\mathrm{MgSO}_{4} \cdot 7 \mathrm{H}_{2} \mathrm{O}(+1 ; 1 \mathrm{~g} / 1)$ through run (24) in our study. Model significance and validity tested by $R^{2}$ values of KA was 0.987 , DM 0.989 and CS 0.9831 and calculated with Derringer's desirability function as 0.937. Glucose represents the most favorable carbon source for kojic acid by Aspergillus species (Rosfarizan and Ariff, 2000). It's believed that the six carbon ring of glucose represented as a precursor for kojic acid synthesis (Megalla et al., 1986). The fungus utilizes glucose molecules initially for its growth, and then later synthesizes kojic acid within the early stationary and decline phase (Kitada $\boldsymbol{e}$ al., 1967). High glucose concentration not necessary utilize in the production it converted to much growing mass of the fungus, which cleared adverse relation between growth and production (Ariff et al., 1996). On the other hand, Futamura et al. (2001) obtained $40 \mathrm{~g} / \mathrm{L}$ of kojic acid by Aspergillus oryzae MK107-39 using corn starch as carbon source. Wan et al. (2005) produced 41g/L KA using glucose, rice bran, $\mathrm{KH}_{2} \mathrm{PO}_{4}$, and $\mathrm{MgSO}_{4}$ by A. oryzae, and Hazzaa et al. (2013) produced $25.5 \mathrm{~g} / \mathrm{L} \mathrm{KA}$ using glucose, ammonium nitrate, $\mathrm{KCl}$, and $\mathrm{MgSO} 4$ by A. oryzae. Yan et al. (2014) produced 33.1g/L KA by A.oryzae M866 using corn stalk, peptone, $\mathrm{KH}_{2} \mathrm{PO}_{4}$ and $\mathrm{MgSO}_{4}$

The traditional optimization process was one-factor-at-a-time method which used in most kojic acid production researches, involves test one factor with keeping the other factors constant under the specific conditions (Alexeeva et al., 2002; Kumar et al., 2003; Patidar et al., 2005; Ahamed et al., 2006). New statistical optimization methods like response surface methodology introduced the main effects and interaction between variables with lowest experimental numbers, saving much time and draw clear pictures for the interaction (De Lima et al., 2010; Zohri et al., 2018; Mahmoud et al., 2020b). Coelho et al. (2010) utilize glycerol as carbon source for kojic acid production using CCD design and obtained $18.8 \mathrm{~g} / \mathrm{l}$ from A. flavus NRRL 626. In this study, optimized kojic acid showed stability against different range of heat stress from $40^{\circ} \mathrm{C}$ to $100^{\circ} \mathrm{C}$ during five continuous hours which may attribute that microbial product usually are more stable than synthetic ones by attaching it with other active groups that guaranty more stability under stress conditions. This stability give it the advantages to be applied in industrial rang tolerate the different extraction and purification process through the industrial process which will need more research on its stability during all these process. Clearly, RSM designs save much time in optimizing kojic acid production with clarity the factorial interaction with less number. Also, Aspergillus oryzae Ao-4 represents a promised industrial potential safe isolate with stable product of kojic acid.

\section{CONCLUSION}

Aspergillus oryzae (Ao-4) represents promising safe isolate for industrial kojic acid production with highly stable product and significant valid experimental design. Response surface methodology offers saving in time during optimizing 
microbial product with clarity the interaction between variables with less number of experiment leading it as one of the most effective and valid way for kojic acid maximization. The selected isolate (Aspergillus oryzae Ao-4) is promised industrial potential safe isolate with stable kojic acid.

\section{REFERENCES}

Ahamad, M.Z., Panda, B.P., Javed, S., Ali, M. (2006). Production of mevastatin by solid-state fermentation using wheat bran as substrate. Res J Microbiol 1, 443 447. https://doi.org/10.3923/jm.2006.443.447

Alexeeva, Y.V., Ivanova, E.P., Bakernina, I.Y., Zyaygintseva, T.N., Mikhailov, V.V. (2002) Optimization of glycosidases production by Pseudoalteromonas issachenkonii KMM 3549T. Lett Appl Microbiol. 35, 343-346. https://doi.org/10.1046/j.1472-765X.2002.01189.x

Ariff, A., Salleh, M., Ghani, B., Hassan, M., Rusul, G., Karim, M. (1996). Aeration and yeast extract requirements for KA production by Aspergillus flavus link. Enzyme Microb Technol 19 (7), 545-550. https://doi.org/10.1016/S0141 0229(96)00065-8

Basappa, S.C., Sreenivasamurthy, V., Parpia, H.A. (1970). Aflatoxin and kojic acid production by resting cells of Aspergillus flavus link. Microbiol 61, 81-86. https://doi.org/10.1099/00221287-61-1-81

Bennett, J.W. (2010). An overview of the genus Aspergillus. In Aspergillus: Molecular Biology and Ge-nomics. Edited by Machida M, Gomi K. Caister Academic, pp: 1-17

Bentley, R. (1957). Preparation and analysis of kojic acid. Method Enzymol 3, 238-241. https://doi.org/10.1016/S0076-6879(57)03381-9

Bentley, R. (2006). From miso, saké and shoyu to cosmetics: a century of science for kojic acid. Nat Prod Rep 23, 1046-1062. https://doi.org/10.1039/b603758p

Booth, C. (1971). The Genus Fusarium. Commonwealth Mycological Insti-tute, Kew Surrey, England. 237.

Bracarense, A.A.P., Takahashi J.A. (2014). Modulation of antimicrobial metabolites production by the fungus Aspergillus parasiticus. Brazilian $J$ Microbiol 45 (1), 313-321. http://dx.doi.org/10.1590/S1517-83822014000100045 Briganti, S., Camera, E., Picardo, M. (2003). Chemical and instrumental approaches to treat hyperpigmentation. Pig Cell Res 16, 101-110. https://doi.org/10.1034/j.1600-0749.2003.00029.x

Brtko, J., Rondahl, L., Fickova, M., Hudecova, D., Eybl, V., Uher, M. (2004) Kojic acid and its derivatives: History and present state of art. Cent Eur J Public Health 12,16-18. PMID:15141965

Burnett, C.L., $\quad$ Bergfeld, W.F., $\quad$ Belsito, D.V., Hill, R.A., Klaassen, C.D. Liebler, D.C., Marks Jr, J.G., Shank, R.C., Slaga, T.J., Snyder, P.W., Andersen, F.A. (2010) Final Report of the Safety Assessment of Kojic Acid as Used in $\begin{array}{lllll}\text { Cosmetics. } & \text { Int } & J & \text { Toxicol } & \text { 29(6):244S-73. }\end{array}$ https://doi.org/10.1177/1091581810385956.

Chang, P.K., Scharfenstein, L.L., Luo, M., Mahoney, N., Molyneux, R.J., Yu, J., Brown, R.L., Campbell, B.C. (2011). Loss of msn A, a Putative Stress Regulatory Gene, in Aspergillus parasiticus and Aspergillus flavus Increased Production of Conidia, Aflatoxin and Kojic Acid. Toxins 3(1), 82-104 https://doi.org/10.3390/toxins3010082

Chen, X., Bai, J., Cao, J., Li, Z., Xiong, J., Zhang, L., Hong, Y., Ying, H. (2009) Medium optimization for the production of cyclic adeno-sine 30,50 monophosphate by Microbacterium sp. no. 205 using response surface methodology. Bioresour Technol 100, 919-924. https://doi.org/ 10.1016/j.biortech.2008.07.062.

Coelho, R.S., Anschau, A., Monte-Alegre, R. (2010). Kojic acid production from glycerol: Optimization using central composite rotatable design. J Biotechno 150, 84. https://doi.org/10.1016/j.jbiotec.2010.08.216

De Lima, J.B.C., Luciana, C.F., Jonas, C. (2010). The use of response surface methodology in optimization of lactic acid production: Focus on medium supplementation, Temperature and pH control. Food technol Biotechnol 48(2), 175-181. https://hrcak.srce.hr/53626

Desai, K.M. (2008). Comparison of artificial neural network (ANN) and response surface methodology (RSM) in fermentation media optimization: case study of fermentative production of scleroglucan. Biochem Eng $J$ 41,266-273 https://doi.org/10.1016/j.bej.2008.05.009

Dobias, J., Brtko, J. (1985). Quantitative determination of kojic acid in fermentation broth of fungi using diffusion in agar plates and by spectrophotometry, Kvas. Prum. 31 (11), 260-262. https://doi.org/10.18832/kp1985061

Domsch, K. H., Gams, W., Anderson, T. H. (1980). Compendium of soil fungi (p. 859). New York: Academic.

El-Kady, I.A., Moubasher, A.H. (1982). Toxigenicity and toxin of Stachybotrys chartarum isolates from wheat straw samples in Egypt. Exper Mycol 6, 25 31.https://doi.org/10.1016/0147-5975(82)90060-3

El-Sharkawy, S.H. (1995). Kojic acid production from cocoa juice by Aspergillus flavus entrapped in calcium alginate. Bollettino Chimico Farmaceutico 134(6), 316-319.PMID:7546538

Faig, J.J., Moretti, A.1., Joseph, L.B., Zhang, Y., Nova, M.J., Smith, K., Uhrich, K.E. (2017). Biodegradable kojic acid-based polymers: controlled delivery of bioactives for melanogenesis inhibition. Biomacromolecules 18 (2),363-373 https://doi.org/10.1021/acs.biomac.6b01353

Frisvad, J.C. (1987). High-performance liquid chromatographic determination of profiles of mycotoxines and other secondary metabolites. J Chromatogr A 392,333-347. https://doi.org/10.1016/S0021-9673(01)94277-3

Futamura, T., Ishihara, H., Tamura, T., Yasutake, T., Huang, G., Kojima, M., Okabe, M. (2001). Kojic acid production in an airlift bioreactor using partially hydrolyzed raw corn starch. $J$ Biosci Bioeng 92, 360-365. https://doi.org/10.1263/jbb.92.360

Gonçalez, M.L., Marcussi, D.G., Calixto, G.M.F., Corrêa, M.A., Chorilli, M. (2015). Structural characterization and in vitro antioxidant activity of kojic dipalmitate loaded w/o/w multiple emulsions intended for skin disorders. Biomed Res Int. Article ID 304591, 8.https://doi.org/10.1155/2015/304591

GoTo, T., Matsui M., Kitsuwa, T. (1990). Analysis of Aspergillus mycotoxins by gas chromatography using fused silica capillary column. Mycotoxins 31, 43-47. https://doi.org/10.2520/myco1975.1990.43

Grahovac, J., Grahovac, M., Dodić, J., Bajić, B., Balaž, J. (2014). Optimization of cultivation medium for enhanced production of antifungal metabolites by Streptomyces hygroscopicus. Crop Protection J 65,143-152. https://doi.org/10.1016/j.cropro.2014.07.020

Hazzaa, M.M., Saad, A.M., Hassan, H.M., Ibrahim, E (2013). High Production of Kojic acid crystals by isolated Aspergillus oryzae var. effuses NRC14. J Appl Sci Res 9(3), 1714-1723.

Ibrahim, A.B.M., Mahmoud, G.A-E. (2019). Nonstoichiometric Mesoporous Cu $1.90 \mathrm{~S}$ Nanoparticles Hydrothermally Prepared from a Copper Anthranilato Complex Inhibit Cellulases of Phytopathogenic Fungi. J Inorg Organomet Polym Mater 29 (4), 1280-1287. https://doi.org/ 10.1007/s10904-019-01091-6

Ibrahim, A.B.M., Zidan, A.S.A., Aly, A.A.M., Mosbah, H.K., Mahmoud, G.A-E. (2020). Mesoporous cadmium sulfide nanoparticles derived from a new cadmium anthranilato complex: Characterization and induction of morphologica abnormalities in pathogenic fungi. Appl Organometal Chem. e5391. https://doi.org/10.1002/aoc.5391

Kitada, M., Ueyama, H., Fukimbara, T. (1967). Studies on kojic acid fermentation (I) Cultural condition in submerged culture. J Ferment Techno 45,1101-1107. http://dl.ndl.go.jp/info:ndljp/pid/10550784

Kong, Y., Zou, P., Miao, L., Qi, J., Song, L., Zhu, L. (2014). Medium optimization for the production of anti-cyanobacterial substances by Streptomyces sp. HJC-D1 using response surface methodology. Environ sci pollut res 21,5983-5990. https://doi.org/10.1007/s11356-014-2532-5

Kumar, D., Jain, V.K., Shanker, G., Srivastava, A. (2003). Utilisation of fruits waste for citric acid production by solid state fermentation. Process Biochem 38 1725- 1729. https://doi.org/10.1016/S0032-9592(02)00253-4

Kwak, M.Y., Rhee, J.S. (1992). Control mycelial growth for kojic acid production using Ca-alginate immobilized fungal cells. Appl Microbiol Bio technol 36, 578-583. https://doi.org/10.1007/BF00183232

Kwak, M.Y., Rhee, J.S. (1991). Cultivation characteristics of immobilized Aspergillus oryzae For kojic acid production. Biotechnol Bioengin 39, 903-906. https://doi.org/10.1002/bit.260390904

Lee, C.Z., Liou, G.Y., Yuan, G.F. (2006). Comparison of the aflR gene sequences of strains in Aspergillus section Flavi. J Microbiol 152, 161-170. https://doi.org/10.1099/mic.0.27618-0

Lin, L., Zhang, J., Wang, P., Wang, Y., Chen, J. (1998). Thin-layer chromatography of mycotoxins and comparison with other chromatographic methods. J Chromatography A, 815(1), 3-20. https://doi.org/10.1016/S00219673(98)00204-0

Liu, J.M., Yub, T.C., Linc, S.P., Hsud, R.J., Hsuc, K.D. and Chengb, K.C (2016). Evaluation of kojic acid production in a repeated-batch PCS biofilmreactor $\quad J \quad$ Biotechnol $\quad 218, \quad 41-48$ https://doi.org/10.1016/j.jbiotec.2015.11.023

Machida, M., Asai, K., Sano, M., Tanaka, T., Kumagai, T., Terai, G., Kusumoto, K.-I.,Arima, T., Akita, O. and Kashiwagi, Y. (2005). Genome sequencing and analysis of Aspergillus oryzae. Nature 438 (7071), 1157-1161. https://doi.org/10.1038/nature04300

Madihah, M.S., Ariff, A.B., Hassan, M.A., Rusul, G. and Karim, M.I.A. (1996) Enhanced kojic acid production by Aspergillus flavus Link in Growth medium containing methanol. ASEAN Food J. 11, 158-162.ID=MY1998050027

Mahmoud, G.A-E., Zidan, A.S.A., Aly, A.A.M., Mosbah, H.K. and Ibrahim, A.B.M. (2019) Calcium and strontium anthranilato complexes as effective Fusarium moniliforme controlling agents. Appl Organometal Chem 33(2), e4740 https://doi.org/10.1002/aoc.4740.

Mahmoud G. A-E., Ibrahim, A.B.M. and Peter Mayer (2020a) Zn(II) and Cd(II) thiosemicarbazones for stimulation/inhibition of kojic acid biosynthesis from Aspergillus flavus and the fungal defense behavior against the metal complexes' excesses. JBIC Journal of Biological Inorganic Chemistry 25:797809.https://doi.org/10.1007/s00775-020-01802-2

Mahmoud G. A-E., Soltan, H.A.H., Abdel-Aleem, W.M. and Osman, S.A.M (2020) Safe natural bio-pigment production by Monascus purpureus using mixed carbon sources with cytotoxicity evaluation on root tips of Allium cepa L. J Food Sci Technol.https://doi.org/10.1007/s13197-020-04758-y. 
Manabe, M.T., Goto, K., Tanaka, M.S. (1981). The capabilities of Aspergillus flavus group to produce aflatoxins and kojic acid. Report National Food Res Inst 38,115- 120.

Masse, M.O., Duvallet, V., Borremans, M. and Goeyens, L. (2001) Identification and quantitative analysis of kojic acid and arbutine in skin-whitening cosmetics Int J Cosmet Sci 23 (4), 219-232. https://doi.org/10.1046/j.14672494.2001.00074.x

Megalla, S.E., Bennett, G.A., Ellis, J.J. and Shotell, O.I. (1986) Production of deoxynivalenol and zearalenone by isolates of Fusarium graminearum SCHW. $J$ Basic Microbiol 26, 415-419. https://doi.org/10.1002/jobm.3620260709

Mohamed, M.H. and Mahmoud, G.A-E. (2018) Microbial gibberellins impact of on Zea mays (L.) plants under different levels of water salinity. Egypt J Soil Sci 58(3), 373-82. https://doi.org/10.21608/ejss.2018.5229.1207

Nafady, N.A., Bagy, M.M.K., Abd-Alla, M.H., Morsy, F.M. and Mahmoud, G.AE. (2015) Improvement of medium components for high riboflavin production by Aspergillus terreus using response surface methodology. Rendiconti Lincei 26(3), 335-344. https://doi.org/10.1007/s12210-015-0449-7

Ogawa, A., Wakisaka, Y., Tanaka, T., Sakiyama, T. and Nakanishi, K. (1995) Production of kojic acid by membrane-surface liquid culture of Aspergillus oryzae NRRL484. J Ferment Bioeng 80(1), 41-45. https://doi.org/10.1016/0922338X(95)98174-J

Patidar, P., Agarwal, D., Banerjee, T. and Patil, S. (2005) Chitinase production by Beauveria feline RD 101: optimization of parameters under solid substrate fermentation conditions World $\mathrm{J}$ Microbiol Biotechnol 21, 93- 95 https://doi.org/10.1007/s11274-004-1553-5

Pildain, M.B., Frisvad, J.C., Vaamonde, G., Cabral, D., Varga, J. and Samson, R.A. (2008) Two novel aflatoxin-producing Aspergillus species from Argentinean peanuts. Int $J$ Syst Evol Microbiol 58 (3),725-735 https://doi.org/10.1099/ijs.0.65123-0

Prabu, R., Rosfarizan, M., Shah, U.K.M. and Ariff, AB. (2011) Improvement of Aspergillus flavus Link S44-1 using random mutational method for kojic acid $\begin{array}{lll}\text { production. Minerva } & \text { Biotechnol 23(4), }\end{array}$ http://psasir.upm.edu.my/id/eprint/22415

Prignano, F., Ortonne, G., Buggiani, G. and Lotti, T. (2007) Therapeutical approaches in melasma. Dermatologic Clinics 25(3), 337-342. https://doi.org/10.1016/j.det.2007.04.006

Raper, K.B., and Fennell, D.I. (1965) The Genus Aspergillus. Williams and Wilkins Co. Baltimore.; IX + 686 .

Rosfarizan, M. and Ariff, A.B. (2000) Kinetics of kojic acid fermentation by Aspergillus flavus using different types and concentrations of carbon and nitrogen

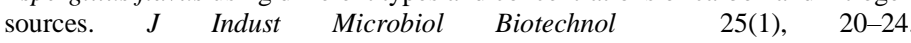
https://doi.org/10.1038/sj.jim.7000017

Sadhasivam, S., Britzi, M., Zakin, V., Kostyukovsky , M., Trostanetsky , A. Quinn, E. and Sionov, E. (2017) Rapid Detection and Identification of Mycotoxigenic Fungi and Mycotoxins in Stored Wheat Grain. Toxins 9, 302. https://doi.org/10.3390/toxins9100302

Santos-Edinum, V.C., Roberto, I.C., Teixeira, M.F.S. and Pessoa, A.J. (2013) Improving of red colorants production in submerged culture and the effect of different parameters in their stability. Biotechnol Prog 29, 778-7785 https://doi.org/10.1002/btpr.1720

Scott, P., Lawrence, J., and Van Walbeek, W. (1970) Detection of mycotoxins by thin-layer chromatography: application to screening of fungal extracts. Appl Microbiol 20(5), 839.PMID: 5485087

Sheikhshoaie, M., Sheikhshoaie, I. and Ranjbar, M. (2017) Analysis of kojic acid in food samples uses an amplified electrochemical sensor employing $\mathrm{V}_{2} \mathrm{O}_{5}$ nanoparticle and room temperature ionic liquid. J Mol Liq 231, 597-601. https://doi.org/10.1016/j.molliq.2017.02.039

Syamsul, K., Mat, R.S., Mohd, F.F.H., Mohd, N.H. and Mohamad, R.M. (2017) Evaluation of tyrosinase activity and radical scavenging activity of Kojic acid and Kojic acid monooleate. Adv Sci Lett 23 (5), 4742-4744. https://doi.org/10.1166/asl.2017.8881

Tanigaki, H., Obata, H. and Tokuyama, T. (1980) The determination of kojic acid using the stopped-flow method. Bull Chem Soc Jpn 53 (11),3195-3197. https://doi.org/10.1246/bcsj.53.3195

Terabayashi, Y., Sano, M., Yamane, N., Marui, J., Tamano, K., Sagara, J. Dohmoto, M., Oda, K., Ohshima, E., Tachibana, K., Higa, Y., Ohashi, S., Koike, H. and Machida M. (2010) Identification and characterization of genes responsible for biosynthesis of kojic acid, an industrially important compound from Aspergillus oryzae. Fungal Genetics Biol 47, 953-961. https://doi.org/10.1016/j.fgb.2010.08.014

Vasntha K.Y., Murugesh, C.S. and Sattur, A.P. (2014) A tyrosinase inhibitor from Aspergillus niger. J Food Sci Technol Mys 51, 2877-2880. https://doi.org/10.1007/s13197-014-1395-6

Vohra, A. and Satyanarayana, T. (2002) Statistical optimization of the medium components by Response Surface Methodology to enhance phytase production by Pichia anomala. Process Biochem 37, 9991004.https://doi.org/10.1016/S0032-9592(01)00308-9

Wakisaka, Y., Segawa, T., Imamura, K., Sakiyama, T. and Nakanishi, K. (1998) Development of a cylindrical apparatus for membrane-surface liquid culture and production of kojic acid using Aspergillus oryzae NRRL484. J Ferment Bioeng 85(5), 488-494.https://doi.org/10.1016/S0922-338X(98)80067-6

Wan, H.M., Chen, C.C., Giridhar, R. and Chang, T.S. (2005) Repeated -batch production of kojic cell retention fermenter using Aspergillus oryzae M3B9. J Ind Microbiol Biotechnol 32, 227-233. https://doi.org/10.1007/s10295-005-0230-5

Wang, K., Li, P.F., Han, C.G., Du, L., Liu, C., Hu, M., Lian, S.J. and Liu, Y.X (2014) Protective effects of kojic acid on the periphery blood and survival of beagle dogs after exposure to a lethal dose of gamma radiation, Radiat Res 182 (6), 666-673. https://doi.org/10.1667/RR13823.1

Xu, C., Kim, S., Hwang, H. and Choi, J. (2003) Optimization of submerged culture conditions for mycelial growth and exobiopolymer production by Paecilomyces tenuipes C240. Process Biochem 38(7), 10251030.https://doi.org/10.1016/S0032-9592(02)00224-8

Yan, S., Tang, H., Wang, S., Xu, L., Liu, H., Guo, Y. and Yao, J. (2014) Improvement of kojic acid production in strain Aspergillus oryzae B008 mutant strain and its uses in fermentation of concentrated corn stalk hydrolysates. Bioprocess Biosystem Eng 37(6),1095-1103. https://doi.org/10.1007/s00449-013$\underline{1081-5}$

Yemm, E.W. and Willis, A.J. (1954) The estimation of carbohydrates in plan extracts by anthrone. Biochem J 57(3), 508-514.PMID: 13181867

Zohri, A.A., Mahmoud, G.A-E., Sadik, N.H., Hanafy, R.A. (2018) Optimization of kojic acid production conditions from cane molasses using Plackett-Burman design. Eur J Biolog Res 8(2), 56-69. https://doi.org/10.5281/zenodo.1211517 